\title{
Synthesis and Characterization of Nickel Urea Thiourea Single Crystal Developed by Slow Evaporation Method
}

\author{
B. SENTHILKUMARAN ${ }^{1}$, S.ARIVOLI $^{2 *}$ and G. THANAPATHY ${ }^{3}$ \\ ${ }^{1}$ Department of Physics, Dharmapuram Adhinam Arts College, \\ Dharmapuram, Mayiladudurai, India \\ ${ }^{2}$ Department of Chemistry, Thiru Vi Ka Government Arts College, Thiruvarur, India \\ ${ }^{3}$ Department of Physics, Poompuhar College, Sirkali, India \\ arivu6363@gmail.com
}

Received 3 January 2017 / Accepted 20 January 2017

\begin{abstract}
A single crystal of nickel urea thiourea has been grown successfully from its aqueous solution. The grown crystals have been subjected to X-ray diffraction studies to identify the morphology and structure. The TGA studies showed the thermal properties of the crystals. The functional group of the grown crystals was identified by UV-Visible double beam spectra, FT-IR analysis, NMR and XRD studies.
\end{abstract}

Keywords: Urea, Thiourea, Nickel sulphate, Nickel urea thiourea single crystal, X-Ray diffraction

\section{Introduction}

The formation of a single crystal structure in materials is affected by its atomic or ionic mobility behaviour. The pressure and temperature are the two parameters that had been used gradually to control and adjust this mobility behaviour. Therefore, the crystal structure formation can be significantly affected temperature and external pressure.Crystal growth is an interdisciplinary subject covering physics, chemistry, material science, chemical engineering, metallurgy, crystallography, mineralogy, etc. In the past few decades, there has been a growing interest on crystal growth processes, particularly in view of the increasing demand of materials for technological applications ${ }^{1-10}$.The major advantages are the anisotropy, uniformity of composition and the absence of boundaries between individual grains, which are essentially present in polycrystalline materials. The strong influence of single crystals in the present day technology is evident from the recent developments in the above mentioned fields. Hence, in order to achieve high performance from the device, good quality single crystals are needed. Crystalline structure is more likely used in many applications compare to the non-crystalline structure. In this paper, the method of crystal growth with emphasis on low temperature solution growth technique was described. 


\section{Experimental}

$0.78 \mathrm{~g}$ of urea, $0.8 \mathrm{~g}$ of thiourea and $1.08 \mathrm{~g}$ of nickel sulphate were dissolved in $30 \mathrm{~mL}$ of double distilled water. The solution was thoroughly mixed using a magnetic stirrer. A crystalline substance was formed. The urea thiourea nickel sulphate solution was prepared in water and maintained at $30{ }^{\circ} \mathrm{C}$ with continuous stirring to ensure homogeneous temperature and concentration. The solution was kept at $30{ }^{\circ} \mathrm{C}$ for twenty days in order to get hard thiourea and urea doped single crystal.

Single crystals of nickel urea thiourea are grown by slow evaporation of the saturated aqueous solution at room temperature. Good qualities of single crystals were grown within twenty days. The photograph of the grown crystal is shown in Figure 1.

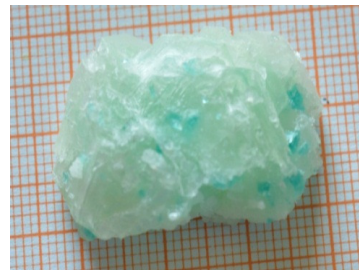

\section{NLO Studies}

Figure 1. Photograph of the (NiTU) single crystal

Kurtz second harmonic generation (SHG) test was performed to find the NLO property of the NiTU single crystals. The crystals were ground into powder and densely packed in between two glass slides. A Q-Switched Nd: YAG laser beam of pulse width 8 ns at a wavelength of $1050 \mathrm{~nm}$ and $10 \mathrm{~Hz}$ fundamental radiation was made to fall normally on the sample cell and measurements were carried out.

\section{Results and Discussion}

\section{$X$-Ray Diffraction analysis}

Single crystal X-ray diffraction study was performed for the grown NiTU crystal. It was found that NiTU crystal belongs to orthorhombic system $\left(\alpha=\beta=\gamma=90^{\circ}\right)$. Lattice parameter values of NiTU are compared with reported TU in Table 1. In the case of doped sample, a slight variation in the cell parameters is observed, which may be due to the incorporation of urea and thiourea ligands. This analysis revealed that the induction of urea and thiourea ligand in the NiTU crystal does not change the crystal system though there is a small change in the lattice parameters. The powder sample of NiTU was scanned over the range $10-80^{\circ}$ at a rate of $1^{\circ}$ per minute and the powder X-ray diffraction patterns were indexed using Check cell software (Figure 2). The Lattice parameter (a) was calculated by selecting the (102) plane using the formula ${ }^{2}$.

$$
\operatorname{Sin}^{2} \theta=\frac{\lambda^{2}}{4 a^{2}}\left(h^{2}+k^{2}+l^{2}\right)
$$

\section{Fourier transforms infrared spectroscopy}

The FT-IR spectra of nickel urea thiourea grown crystals are shown in Figure 3. In the higher wavelength region, the peak at $3470 \mathrm{~cm}^{-1}$ is assigned to $\mathrm{C}-\mathrm{H}, \mathrm{N}-\mathrm{H}$ stretching vibration. The region $3450 \mathrm{~cm}^{-1}$ and $3150 \mathrm{~cm}^{-1}$ with strong intensity represents $\mathrm{N}-\mathrm{H}$ stretching mode. The broad envelope positioned in between $3450 \mathrm{~cm}^{-1}$ and $2615 \mathrm{~cm}^{-1}$ corresponds to the symmetric and asymmetric stretching modes of $\mathrm{NH}_{2}$ group. The peak at $2970-2910 \mathrm{~cm}^{-1}$ with medium intensity refers $\mathrm{C}-\mathrm{H}$ asymmetric stretching. Combinational overtones extend to the bands from $2300-2250 \mathrm{~cm}^{-1}$. The peak at $1730 \mathrm{~cm}^{-1}$ indicating the $\mathrm{C}=\mathrm{O}$ stretching mode of vibration. 
The $\mathrm{NH}_{2}$ bending vibrations occur at 1608,1593 and $820 \mathrm{~cm}^{-1}$. The peak at $1540 \mathrm{~cm}^{-1}$ is due to $\mathrm{NH}_{2}$ bending vibration. The peaks at $1440-1390 \mathrm{~cm}^{-1}$ corresponds to the $\mathrm{C}=\mathrm{S}$ stretching. The $\mathrm{C}-\mathrm{C}$ stretching mode of vibration occurs in $1330 \mathrm{~cm}^{-1}$ peak. The peak at $1205 \mathrm{~cm}^{-1}$ gives rise to C-N stretching mode of vibration. The spectra show absorption bands in the region of 1090 $\mathrm{cm}^{-1}$ and $1045 \mathrm{~cm}^{-1}$ which are due to in-plane $\mathrm{C}-\mathrm{H}$ bending vibration. The band $1080 \mathrm{~cm}^{-1}$ signifies the N-H symmetric bending. The bands at $830 \mathrm{~cm}^{-1}$ and $795 \mathrm{~cm}^{-1}$ revealed that C-N deformation mode. The ring deformation occurs at $815 \mathrm{~cm}^{-1} . \mathrm{C}=\mathrm{O}$ deformation is identified by the band at $678 \mathrm{~cm}^{-1}$. C-H out-of plane bending peaks obtained at $660 \mathrm{~cm}^{-1}$ and $648 \mathrm{~cm}^{-1}$. The bands $668-632 \mathrm{~cm}^{-1}$ represents $\mathrm{C}-\mathrm{C}$ deformation. The absorption bands in the region of 476$463 \mathrm{~cm}^{-1}$ are due to N-C stretching vibration. The assignments confirm the presence of various functional groups present in the material. The absorption around $1600 \mathrm{~cm}^{-1}$ is $\mathrm{NH}_{2}$ bending and this band would be shifted into lower wavelength region $1618 \mathrm{~cm}^{-1}$. Our investigations are well compared with earlier reports ${ }^{10-19}$.

Table 1. Lattice parameter values of NiNTU and reported TU crystals

\begin{tabular}{ccccccc}
\hline \multirow{2}{*}{ Sample } & \multirow{2}{*}{ System } & \multirow{2}{*}{ 20(degree) } & \multirow{2}{*}{ FWHM } & \multirow{2}{*}{ hkl } & \multicolumn{2}{c}{ Lattice parameter $(\AA)$} \\
\cline { 6 - 7 } & & & & & Calculated & Reference[2] \\
\hline \multirow{2}{*}{ TU } & \multirow{2}{*}{ Orthorhombic } & 23.25 & 0.16 & 200 & 7.644 & 7.644 \\
& & 32.57 & 0.16 & 020 & 8.527 & 8.559 \\
& & 28.4935 & 0.24 & 002 & 5.493 & 5.492 \\
\hline \multirow{2}{*}{ NiTU } & \multirow{2}{*}{ Orthorhombic } & 19.7727 & 0.448 & 020 & 3.8300 & 3.9650 \\
& & 20.6897 & 0.5033 & 002 & 4.4864 & 4.5002 \\
& & &
\end{tabular}

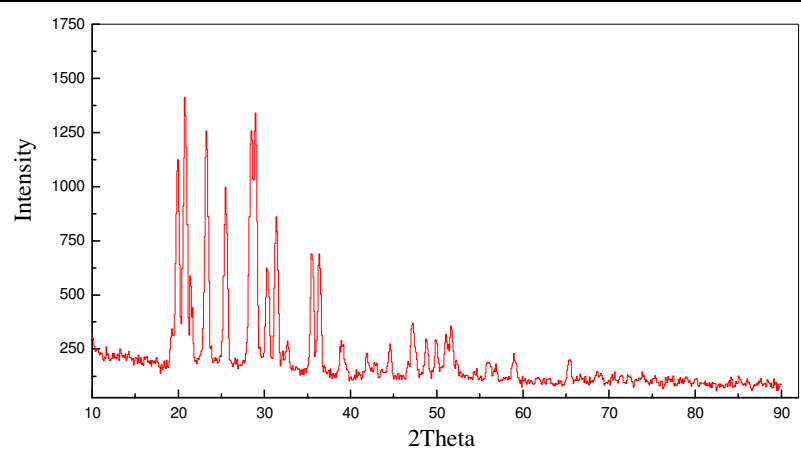

Figure 2. XRD pattern of the NiTU single crystal

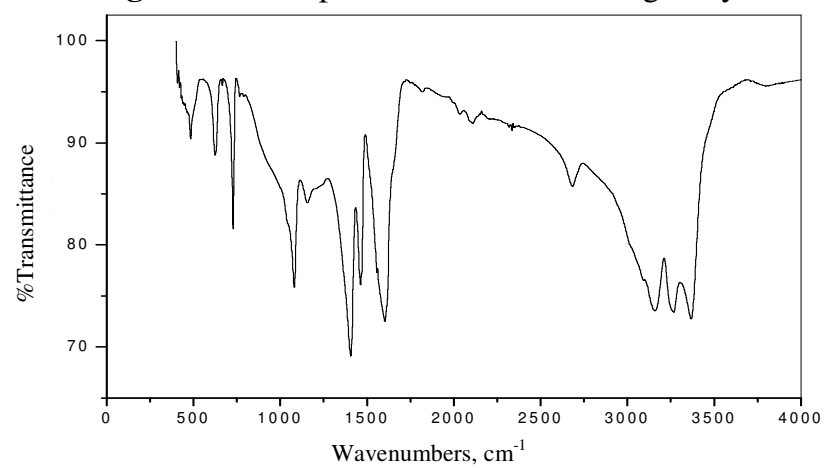

Figure 3. FT-IR spectrum of the NiTU single crystal 


\section{$U V$ - Visible studies}

The UV-Visible spectrum of the single crystal NiTU shown in Table 2 indicates low absorption in the entire visible and near infrared region of the crystals. This is a desirable property for NLO applications since a wider optical transparency in these regions enhances the frequency conversion efficiency in the corresponding wavelengths.

The lower cuts off wavelengths of NiTU single crystal were found to be $279.2 \mathrm{~nm}$, $311.5 \mathrm{~nm}, 340.9 \mathrm{~nm}$ and $480.8 \mathrm{~nm}$ respectively. The above values indicates the presence chromophores such as amino, imino, carbonyl and thio carbonyl groups and the good optical transmittance in the entire visible region and the lower cut off wavelength $\left(\lambda_{\text {cut }}\right)$ was observed as this is due to $\pi-\pi^{*}$ transition in the compounds. The band gap energy $\left(\mathrm{E}_{\mathrm{g}}=\mathrm{hc} / \lambda\right)$ was found to be $3.87 \mathrm{eV}$ for pure and nickel urea thiourea crystals. The large transmission in the entire visible region and short cut off wavelength enables it to be a potential material for second and third harmonic generation ${ }^{15-27}$.

Table 2. UV-Visible spectrum data of NiTU Crystal

\begin{tabular}{ccc}
\hline Crystal & Wavelength $(\mathrm{nm})$ & \% Transmittance \\
\hline \multirow{3}{*}{ NiTU } & 279.2 & 68.5 \\
& 311.5 & 63.1 \\
& 340.9 & 87.9 \\
& 480.8 & 91.2 \\
\hline
\end{tabular}

\section{Nuclear magnetic resonance spectroscopy}

NMR spectrum of NiTU was recorded using FT-NMR spectrometer. NiTU crystal was powdered and dissolved in deuterated dimethyl sulfoxide (DMSO). NMR spectrum recorded for NiTU is shown in Figure 4. A chemical shift at 7.708-7.831ppm is due to $=\mathrm{C}-\mathrm{NH}-\mathrm{C}=$ proton. The chemical shift at 7.371-7.458 ppm is assigned to $\mathrm{O}-\mathrm{C}=\mathrm{O}$ and $\mathrm{N}-\mathrm{H}$ proton. Chemical shift at 9.280-9.714 ppm is due to $-\mathrm{N}-\mathrm{C}=\mathrm{O}$. A chemical shift at $1.16 \mathrm{ppm}$ is due to $=\mathrm{C}-$ proton $^{12}$. The chemical shift at 7.269-7.306 is due to $\mathrm{H}-\mathrm{N}-\mathrm{C}=\mathrm{O}$. A chemical shift at 3.528 is due to $-\mathrm{C}=\mathrm{S}$. The above values confirm the structure of NiTU.

\section{Thermal analysis}

TGA analysis of the NiTU crystal was carried out in the temperature range $10-900{ }^{\circ} \mathrm{C}$. The recorded thermogram is shown in Figure 5. From TGA curve it is observed that the weight loss start from $300{ }^{\circ} \mathrm{C}$. There is $11.9 \%$ weight loss between $320^{\circ} \mathrm{C}$ and $350^{\circ} \mathrm{C}$. This weight loss is due to the liberation of $\mathrm{NH}_{3}$. There is $17 \%$ weight loss between $575^{\circ} \mathrm{C}$ and $690{ }^{\circ} \mathrm{C}$. This weight loss is due to the liberation of CO. There is $25 \%$ weight loss between $850{ }^{\circ} \mathrm{C}$. This weight loss is due to the liberation of $\mathrm{H}_{2} \mathrm{~S}$. This endothermic event is in good agreement with the TGA trace ${ }^{21}$.

\section{Micro hardness studies}

Hardness of the material is a measure of resistance that offers to deformation. The transparent polished crystal free from cracks was selected for hardness measurements. The indentations were made on the flat surface with the load ranging from 25 to $100 \mathrm{~g}$ using Shimadzu make-model-HMV-2 fitted with Vicker's pyramidal indenter and attached to an incident light microscope. The indentation time was kept as $5 \mathrm{~s}$ for all the loads. The Vicker's hardness (Hv) was calculated from the relation ${ }^{21}$,

$$
H v=\frac{1.8544 P}{d^{2}} P / d^{2} \mathrm{~kg} / \mathrm{mm}^{2}
$$


Where, $\mathrm{P}$ is the applied load and $\mathrm{d}$ the average length of the diagonal of the indentation mark. With $\mathrm{P}$ in $\mathrm{g}$ and $\mathrm{d}$ in $\mu \mathrm{m}$, the units of $\mathrm{Hv}$ turned out to be $\mathrm{kg} / \mathrm{mm}^{2}$. The variation of micro hardness with applied load for the prominent (102) plane of the NiTU crystal is shown in Figure 6. It is found that the hardness values increases with the increase of the applied load. This behaviour of increasing micro hardness with the load known as reverse indentation size effect (RISE) $^{21}$, which is also attributed due to existence of distorted zone near crystal medium interface, effect of vibrations, specimen chipping etc., and the plastic deformation is dominant. At low loads or strains, plastic deformation of crystals mainly involves the nucleation of dislocations along a particular slip system. The RISE effect can be qualitatively explained on the basis of the depth of penetration of the indenter ${ }^{21}$. At small loads, the indenter penetrates only the surface layers and therefore, the effect is shown sharply at the early stages. When the applied load increases, the penetration depth also increases and the overall effect must be due to the surface and inner layers. When only one slip system is active during plastic deformation at low loads, the number of active parallel glide planes during indentation is low. Therefore the nucleating dislocations rapidly propagate into the material without experiencing substantial mutual interaction stress between them. Consequently in this stage, indentation depth increases proportionally with applied pressure.

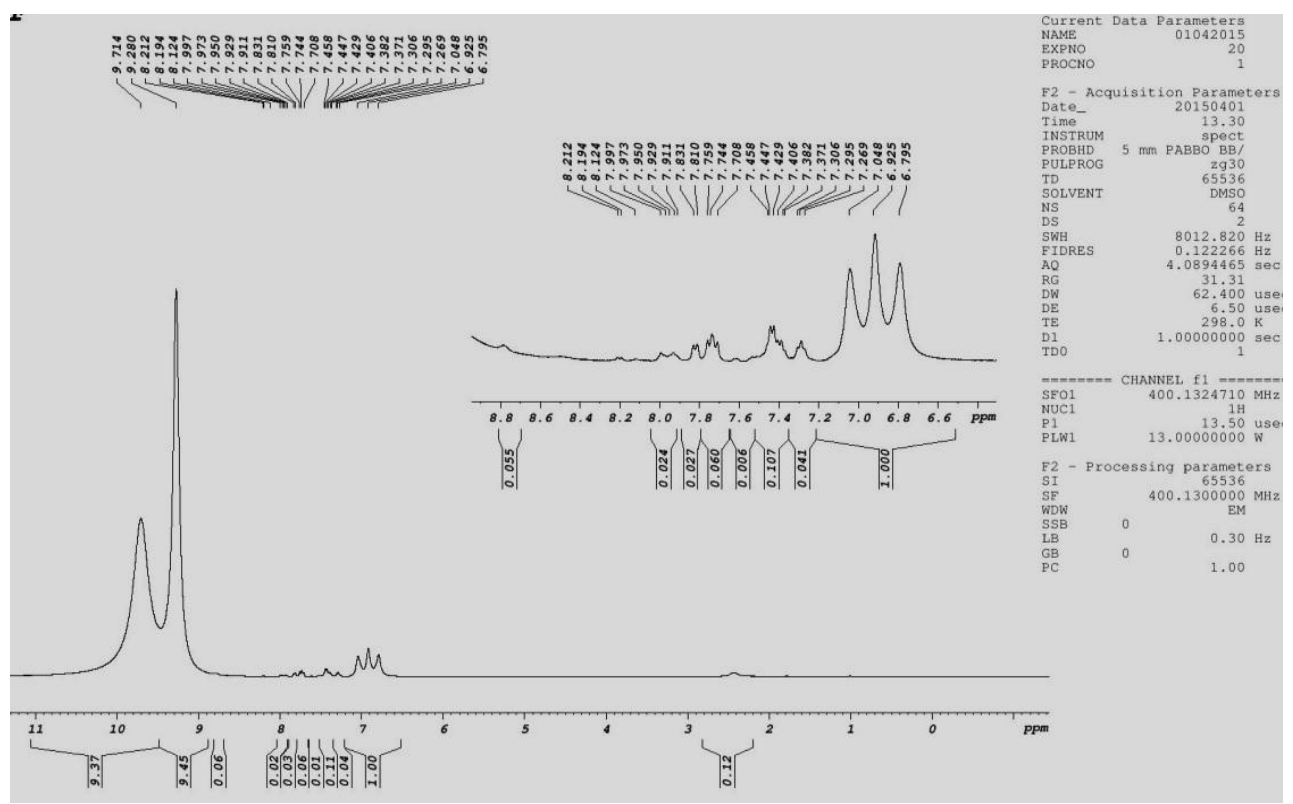

Figure 4. NMR spectrum of the NiTU single crystal

\section{NLO Studies}

The second harmonic signal, generated in the crystals was confirmed from the emission of green radiation by the crystals. The NLO SHG values of the NiTU single crystals were determined and compared to the reported SHG value of pure $\mathrm{KDP}^{21,27}$ is shown in Table 3 .

Table 3. The NLO SHG value of pure KDP

\begin{tabular}{ccc}
\hline Crystal & $\begin{array}{c}\text { Second harmonic signal } \\
\text { output }(\mathrm{mJ})\end{array}$ & $\begin{array}{c}\text { SHG efficiency (compared to } \\
\text { SHG efficiency of pure KDP) }\end{array}$ \\
\hline NiTU & 2.1 & 0.08 \\
\hline
\end{tabular}




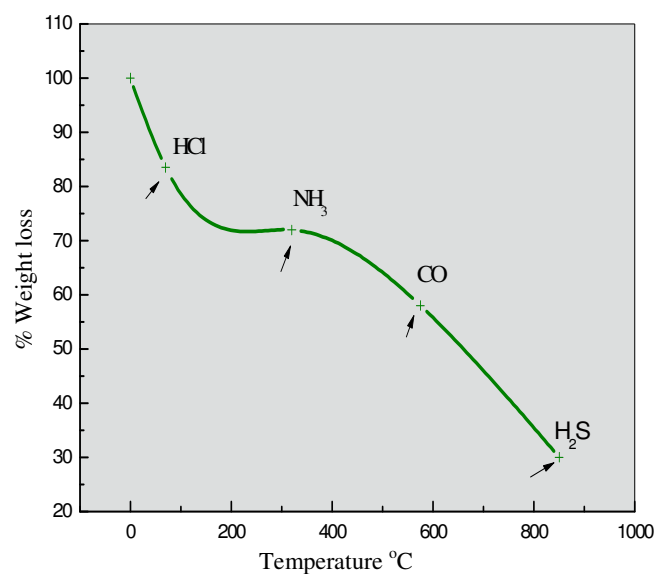

Figure 5. Thermogravimetric analysis for the determining the weight loss

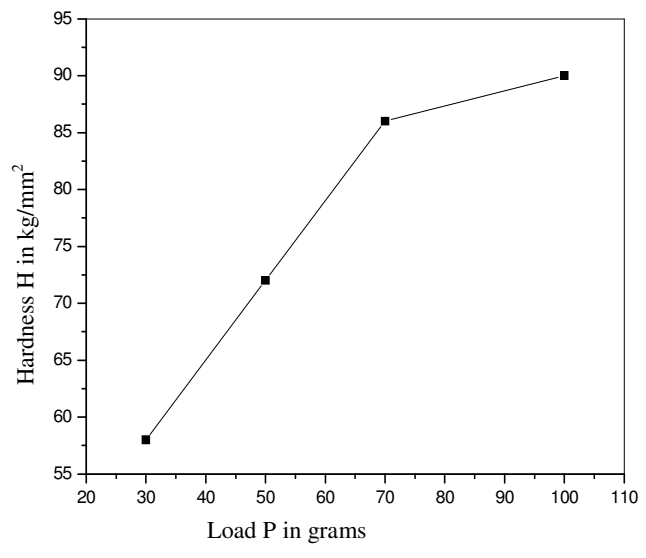

Figure 6. Variation hardness number with Load

\section{Conclusion}

The good quality single crystals ofnickelurea thiourea are successfully grown by slow evaporation method at room temperature.The UV-Vis spectra showed that the crystals had a wide optical window, no absorbance and good optical transmittance in the entire visible region. FT-IR analysis confirmed the presence of functional groups in the grown crystals.TGA thermogram revealed the thermal stability of the materials. The powder X-Ray diffraction study confirms the lattice parameter values. The good optical quality and their suitability for NLO applications. Kurtz-Perry powder SHG test was employed to determine the SHG efficiency of the samples and the values were compared to the reported SHG efficiency of pure KDP.

\section{References}

1. Saha J K and Podder J, J Bangladesh Academy of Sciences, 2011, 35(2), 203-210; DOI:10.3329/jbas.v35i2.9426

2. Viruthagiri G, Praveen P, Mugundan S and Anbuvannan M, Indian J Adv Chem Sci., 2013, 1(4), 193-200.

3. Sundararajan R S, Senthilkumar M and Ramachandraraja C, J Crystallization Process Technology, 2013, 3, 56-59; DOI:10.4236/jcpt.2013.32008

4. Gunasekaran S, Anand G, Arun Balaji R, Dhanalakshmi J and Kumaresan S, J Phys., 2010, 75(4), 683-690; DOI:10.1007/s12043-010-0148-y

5. Thomas Joseph Prakash J and Ruby Nirmala L, Int J Comp Appl., 2011, 6, 0975-8887.

6. Duan X E, Wei X H, Tong H B and Bai S D, J Mole Struct., 2011, 1005(1-3), 91-99; DOI:10.1016/j.molstruc.2011.08.030

7. KrishnaMoha M N, Jagannathan K, Ponnusamy S and Muthamizhchelvan C, J Phys Chem Solids, 2011, 72(11), 1273-1278; DOI:10.1016/j.jpcs.2011.07.020

8. Muthu K and Meenakashisundaram S P, J Crystal Growth, 2012, 352(1), 158-162; DOI:10.1016/j.jcrysgro.2012.01.024

9. Chandrasekaran J, Ilayabarathi P, Maadeswaran P, Mohamed Kutty P and Pari S, Optics Commun., 2012, 285(8), 2096-2100; DOI:10.1016/j.optcom.2011.12.063

10. Chandrasekaran J, Ilayabarathi P and Maadeswaran P, Rasayan J Chem., 2011, 4(2), 320-326. 
11. Krishnakumar V and Nagalakshmi R, Spectrochimica Acta Part A: Molecular Biomolecular Spectroscopy, 2007, 68(3), 443-453; DOI:10.1016/j.saa.2006.11.049

12. Vijayan N and Ramesh Babu R, J Crystal Growth, 2004, 267(3-4), 646-653; DOI:10.1016/j.jcrysgro.2004.04.008

13. Mohankumar R and Rajanbabu D, Jayaramanc D, Jayaveld R and Kitamura K, $J$ Crystal Growth, 2005, 275(1-2), 1935-1939; DOI:10.1016/j.jcrysgro.2004.11.260

14. Merry H O, Warren L F, Appl Optics, 1992, 31(24), 5051-5060; DOI:10.1364/AO.31.005051

15. Venkataraman V, Dhavaraj G and Bhat H L, J Crtys Growth, 1995, 154(1-2), 92-97; DOI:10.1016/0022-0248(95)00212-X

16. Hanna M C, Lu Z H, Cahill A F, Heben M J and Nozik A J, J Crystal growth, 1997, 174(3-4), 605-610; DOI:10.1016/S0022-0248(97)00029-8

17. Cu D, Jiaog M and Taus Z, Acta Chimica Sinica, 1983, 41(6), 570-573.

18. Ramachandraraja C and Sundararajan R S, Spectrochimica Acta Part A, 2008, 71(4), 2008, 1286-1289; DOI:10.1016/j.saa.2008.03.028

19. Kurtz S K and Perry T T, J Appl Phys., 1968, 39(8), 3798-3814; DOI:10.1063/1.1656857

20. Martin Britto Dhas S A, Suresh J, Bhagavannarayana G and Natarajan S, Open Crystallography J, 2008, 1, 46-50; DOI:10.2174/1874846500801010046

21. Ruby A and Alfred Cecil Raj S, Int J Sci Res Publications, 2013, 3(3), 1-5.

22. Lawrence G M and Thomas Joseph Prakash J, Spectrochimica Acta Part A, 2012, 91, 30-34; DOI:10.1016/j.saa.2012.01.055

23. Patel J D, Mighri F and Ajji A, Materials Letters, 2012, 74, 183-186; DOI:10.1016/j.matlet.2012.01.089

24. Patel J D, Mighri F, Ajji A and Chaudhurid T K, Mater Chem Phys., 2012, 132(2-3), 747-755; DOI:10.1016/j.matchemphys.2011.12.006

25. Anandan P, Jayavel R, Saravanan T, Parthipan G, Vedhi C and Mohan Kumar R, Optical Materials, 2012, 34(7), 1225-1230; DOI:10.1016/j.optmat.2012.01.042

26. Joema S E, Perumal S and Ramalingam S, Recent Res Technol., 2011, 3, 2076-5061.

27. Ramajothi J, Dhanuskodi S and Akkurt M, Spectrochimica Acta Part A, 2008, 69(4), 1271-1276; DOI:10.1016/j.saa.2007.07.019 